\title{
Maternal consumption of pulque, a traditional central Mexican alcoholic beverage: relationships to infant growth and development
}

\author{
Jeffrey R Backstrand ${ }^{1, *}$, Lindsay H Allen ${ }^{2}$, Eulalia Martinez ${ }^{3}$ and Gretel H Pelto ${ }^{4}$ \\ 'Department of Nutrition \& Food Studies, New York University, 35 West 4th Street, 10th Floor, New York, NY \\ 10012, USA: ${ }^{2}$ Department of Nutrition, 3135 Meyer Hall, University of California, One Shields Avenue, Davis, CA \\ 95616-8966, USA: ${ }^{3}$ Division de Nutrición de Comunidad, Instituto Nacional de la Nutrición Salvador Zubirán, \\ Vasco de Quiroga \#15, Tlalpan Mexico City DF, DF 1400, Mexico: ${ }^{4}$ Division of Nutritional Sciences, 210 Savage \\ Hall, Cornell University, lthaca, NY 14853-6301, USA
}

Submitted 15 June 2000: Accepted 16 January 2001

\begin{abstract}
Objectives: To document the consumption during pregnancy of pulque, a traditional central Mexican alcoholic beverage, and its relationship to subsequent infant size, physical growth and performance on the Bayley Scales of Infant Development.

Design: Prospective cohort study.

Setting: Six villages in rural, central Mexico in 1984-1985.

Subjects: Seventy mother-infant pairs.

Results: Most women (72.9\%) consumed pulque during pregnancy, and 28.6\% consumed more than $150 \mathrm{~g}$ ethanol week ${ }^{-1}$ from the beverage. Individuals who consumed pulque showed no compensating decrease in energy obtained from other foods. Pulque consumption possessed curvilinear relationships with both infant length (at 1 and 6 months) and Bayley mental performance (at 6 months). Heavy pulque intakes were associated with smaller infant size and poorer mental performance. In modest quantities, pulque consumption may have been beneficial due to its micronutrient content.

Conclusions: Intakes of alcohol from pulque were common among pregnant women in these rural, central Mexican villages. Given current scientific knowledge of the adverse effects of ethanol on foetal development, public health interventions are needed to reduce heavy pulque consumption during pregnancy in some areas of rural Mexico.
\end{abstract}

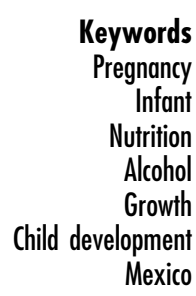

Alcoholic beverages comprise an important part of diets throughout much of the world. In the industrialised countries, alcohol often provides $10 \%$ or more of adult energy intakes ${ }^{1}$. Alcoholic beverages, if not distilled or overly processed, can also provide significant amounts of vitamins and minerals. Therefore, where micronutrient intakes are marginal, as is often the case in the developing countries, alcoholic beverages can be nutritionally significant $^{2}$.

Pulque, a beverage brewed from the sap of several Agave species, has long been a staple of the central Mexican diet ${ }^{3,4}$. For centuries, the mildly alcoholic beer ( $\sim 4-6 \%$ ethanol by volume) has been regarded as healthy when consumed in moderation, and as possessed of medicinal qualities 5 . Indeed, pulque can provide important quantities of ascorbic acid, iron, and riboflavin - all nutrients consumed in low amounts by many individuals living in rural, central Mexico ${ }^{6-9}$. Pulque also contains significant quantities of steroidal saponins, many of which are bioactive ${ }^{10}$. Saponins present in Agave species have shown hypocholesterolemic, anti-inflammatory and antibiotic activity, but the functional effects of those in pulque remain unexplored ${ }^{11-13}$. Contrary to popular belief, pulque does not appear to contain psychoactive substances ${ }^{14}$.

Ethanol consumption during pregnancy can adversely affect child growth and development ${ }^{15,16}$. Foetal Alcohol Syndrome (FAS), a dramatic effect of foetal ethanol exposure, is characterised by a triad of disordered growth, facial abnormalities and behavioural/cognitive impairments ${ }^{1,17}$. More common and less frequently diagnosed are Alcohol-Related Birth Defects (ARBD) and Foetal Alcohol Effects (FAE). The latter represent a broad spectrum of negative outcomes that fall short of classic 
FAS, but which include adverse effects on growth, cognitive performance and behaviour ${ }^{16}$.

In the developing countries, impaired child growth and development often occurs independently of any effect of alcohol. The World Health Organization estimates that $32.5 \%$ of children in the developing countries are 'stunted' (defined as stature falling $<2$ standard deviations (SD) below the median on standard growth curves) ${ }^{18}$. This stunting is often associated with adverse neurobehavioural outcomes ${ }^{19,20}$. Because in the developing countries foetal alcohol exposure often occurs within a biological and social environment that fails to permit optimal child growth and development, even in the absence of alcohol intake, maternal alcohol consumption in such populations has a particularly strong potential to directly and indirectly compromise child growth and development.

The current paper describes pulque consumption in a rural area of the central Mexican highlands. Subjects are 70 pregnant women and their subsequent infants. Because little has been written about pulque consumption during pregnancy, the paper describes in some detail: (1) patterns of drinking; (2) the contribution of pulque consumption to nutrient intake in pregnancy; and (3) the relationships of pulque intake during pregnancy to infant size, growth, and Bayley motor and mental performance.

\section{Subjects and methods}

\section{The Mexico Nutrition CRSP}

Data were collected as part of the Mexico NCRSP (Collaborative Research and Support Program on Human Nutrition), a prospective cohort study focused on the effects of marginal malnutrition on human function. The project was a collaboration between the University of Connecticut and the Instituto Nacional de la Nutrición Salvidor Zubirán (INNSZ) in Mexico City ${ }^{21}$. Project protocols were approved at both institutions by committees on the use of human subjects in research.

\section{Research setting}

Fieldwork was conducted between 1982 and 1986 in six small villages in the Solís Valley, a rural area in the central Mexican highlands at altitude of approximately $2400 \mathrm{~m}$. Located about $100 \mathrm{~km}$ north-west of Mexico City, the predominant local economic activities were subsistence maize farming and low-skill wage labour. Household incomes were often supplemented by cash earned in Mexico City and other urban centres.

\section{Subjects}

From November 1984 to December 1985, 115 singleton births occurred in the six NCRSP villages. At 6 months of age, $89(77.4 \%)$ infants were assessed by a project psychologist using the Bayley Scales of Infant Development ${ }^{22}$. This paper presents data on a subset of 70 mother-infant pairs with infant weight and length measures at 1 month, and at least 4 days of maternal dietary data collected during pregnancy. Subjects $(N=70)$ and non-subjects $(N=45)$ did not differ significantly by gender, community, household material wealth, household size, maternal education, or the proportion of time the male was present in the household. In this population, infants and young children were generally breast-fed. Complementary feeding usually began after 3 months of age.

\section{Antbropometry}

A project physician closely supervised and standardised all anthropometric measurements ${ }^{23}$. Maternal measures were collected either at the Solís Clinic or at home, and were scheduled once per month during pregnancy and the postnatal period. Infant anthropometry was scheduled for collection at birth, 8 days, 30 days, and once per month until age 8 months. Infants born at the Solís Clinic were weighed on a Salter infant scale, while older infants and infants born at home were weighed on a batteryoperated digital scale (accurate to $0.1 \mathrm{~kg}$ ). Infant lengths were measured with a steel tape; wooden blocks were used to locate the top of the head and bottom of the feet. A SAS program employing algorithms published by Dibley et al. was used to calculate weight-for-age, length-for-age and weight-for-length $Z$-scores ${ }^{24}$. Growth was measured as residual size when 6-month weight or length was regressed on 1-month weight or length ${ }^{25}$.

\section{Bayley Scales of Infant Development}

A single, trained project psychologist (EM) assessed infants at 6 months of age using the Bayley Scales of Infant Development ${ }^{22}$. Based on the age of the children, the examiner used 51 Mental Scale (MDI) items (items 4090) and 26 Motor Scale (PDI) items (items 15-40). All Bayley assessments were conducted at a single session in the infant's home. Bayley motor and mental scores are presented both as raw scores and as scores adjusted for age using the Bayley 'norms' - the MDI (mental scale) and PDI (motor scale).

\section{Infant and maternal diets}

Staff nutritionists assessed dietary intake by a combination of dietary recall, food record and food weighing during two consecutive 24-hour periods per month ${ }^{21}$. Maternal data were collected beginning at enrolment in the study (soon after pregnancy was identified) until 8 months postpartum. Daily nutrient intakes were estimated using the UCB International Minilist, a nutrient database created specifically for use by the Nutrition $\mathrm{CRSP}^{26}$. Summary dietary variables are means of daily intakes. Mothers had a mean of $9.9 \pm 5.5$ days of dietary data in pregnancy, and $11.2 \pm 2.0$ days postpartum. 
Table 1 The Mexican Recommended Dietary Intakes (RDI) during pregnancy for selected nutrients, and the nutrient content of 0.5 litre of pulque, which was the median quantity consumed per sitting by the sample of 70 women

\begin{tabular}{|c|c|c|c|c|}
\hline & \multicolumn{2}{|c|}{ Content per 0.5 litre } & \multirow[b]{2}{*}{ Mexican RDI† } & \multirow[b]{2}{*}{$\%$ of RDI per 0.5 litre } \\
\hline & Mexican Food Tables ${ }^{*}$ & Sanchez-Marroquin ${ }^{29}$ & & \\
\hline Energy (kcal) & 215 & NA & 2385 & 9.0 \\
\hline Ethanol $(\mathrm{g})$ & $23.5 \S$ & $14.5-32.5$ & - & - \\
\hline Ascorbic acid (mg) & 30 & NA $\ddagger$ & 70 & 42.9 \\
\hline Thiamin (mg) & 0.1 & $0.025-0.145$ & 1.5 & 6.7 \\
\hline Riboflavin (mg) & 0.1 & $0.090-0.165$ & 1.7 & 5.9 \\
\hline Iron (mg) & 3.5 & NA $\ddagger$ & 24 & 14.6 \\
\hline
\end{tabular}

* Source: Hernandez et al. ${ }^{6}$.

† Source: Instituto Nacionál de la Nutrición Salvidor Zubirán ${ }^{36}$

$\ddagger \mathrm{NA}=$ not available.

$\S$ Value not provided in Mexican Food Tables, but based on the midpoint of the range of ethanol values $\left(47 \mathrm{~g} \mathrm{I}^{-1}\right)$ provided by Sanchez-Marroquin ${ }^{29}$.

\section{Nutrients, etbanol and pulque consumption}

Information on the nutrient content of pulque derives from work done 50 years ago by Cravioto et $a l^{27,28}$. In 1977, Sanchez-Marroquin ${ }^{29}$ (cited by Steinkraus ${ }^{5}$ ) provided additional information on the alcohol, B-vitamin and amino acid content of pulque in the form of ranges, and showed the nutrient content of pulque to be highly variable when produced by traditional, small-scale methods (Table 1 ). The Cravioto values ${ }^{27,28}$ continue to be those employed in the Mexican Food Composition Tables $^{6}$, and provide the basis for the values presented in this paper.

Ethanol intakes were estimated from the dietary intake data. For these 70 women, all ethanol came from pulque. Daily alcohol intakes were calculated using a value of $47 \mathrm{~g}$ of ethanol $1^{-1}$ of pulque, the midpoint of the range (29-65 $\mathrm{g} \mathrm{l}^{-1}$ ) provided by Sanchez-Marroquin ${ }^{29}$. Pulque consumption during pregnancy and lactation is presented as mean energy intake per recall day, and mean alcohol intake per week. Other alcohol intake variables are (1) mean intake per drinking day, (2) mean intake per 'drinking event', (3) the percentage of days drinking, and (4) the mean number of drinking events per drinking day. In the text, pulque consumption refers to mean intake across all recall days unless otherwise stated.

\section{Blood collection and analysis}

Blood data, collected during the third trimester, were available for just 49 pregnant mothers. Subjects were asked to fast overnight, and were transported in the morning to the Solís Clinic for phlebotomy. Venous blood was drawn using ethylene diamine tetraacetic acid (EDTA) as the anticoagulant, and samples were transported on ice to INNSZ in Mexico City within about four hours. Haematological analyses were performed using an electronic counter (model ZF, Coulter Electronics, Hialeah, FL). The INNSZ haematology laboratories provided controls that were analysed daily between samples, and duplicate samples were checked once per week. Plasma ferritin was assessed in duplicate with an
RIA (radio-immunoassay) kit (Ferrizyme, Abbott Laboratories, Berkeley, CA).

\section{Social and other variables}

Mexico NCRSP staff collected extensive socio-economic data, including information on household ownership of material goods and house construction. Earlier, a measure of household material wealth was constructed based on a principal components analysis of these data ${ }^{30}$. This variable has proved to be a good predictor of household and individual food intake ('dietary quality') in this population $^{30,31}$. Other variables employed in this paper include self-reported level of maternal education, and the estimated energy needs of the household (based on the age, sex and weights of household members $)^{32}$.

\section{Statistical analyses}

All statistical analyses were conducted using SAS (SAS Institute, Cary, NC). Spearman correlations are employed in the dietary analyses because of skewed food and nutrient intake variables. All $P$-values are two-tailed. In the regression analyses, pulque intake per day was transformed (square root) to improve a skewed distribution. Interaction effects and curvilinear relationships were investigated using centred data; residual plots and influence statistics were used to assess the adequacy of the regression models ${ }^{33}$.

PROC LOESS, which employs a locally weighted regression technique (loess), was also used to model the curvilinear pulque relationships ${ }^{34}$. Unlike classical regression, the loess technique does not require the researcher to specify a function (i.e. linear, quadratic, etc.) for use in modelling the data ${ }^{35}$. Loess curves were fitted using the direct method and iterative reweighting to improve robustness of fit and resistance to outliers.

\section{Results}

Of 70 women, $72.9 \%$ consumed pulque during pregnancy and $75.7 \%$ consumed the drink during the postpartum period. As would be expected, intakes of pulque during 
the two time periods were highly correlated $(r=0.67$, $P<0.0001, \quad N=70$ ). Of 19 'non-consumers' during pregnancy, $52.6 \%$ reported pulque consumption later during the postpartum period. Of 17 postpartum 'nonconsumers', $47.1 \%$ reported pulque consumption earlier during pregnancy.

For those mothers identified as pulque drinkers during pregnancy $(N=51)$, the beverage provided a median of $108 \mathrm{kcal}(450 \mathrm{~kJ})$ and $11.8 \mathrm{~g}$ ethanol day ${ }^{-1}(82 \mathrm{~g}$ week ${ }^{-1}$ ). The latter quantity is roughly equivalent to daily consumption of a $12 \mathrm{oz}$ bottle of 'light' beer. Intakes by some women were considerably higher, and nearly a third of pregnant women (28.6\%) consumed more than $150 \mathrm{~g}$ ethanol week ${ }^{-1}$, levels of intake that have been associated with increased risk of foetal alcohol effects $(\mathrm{FAE})^{15}$. One pregnant woman reported drinking $81 \mathrm{~g}$ ethanol day ${ }^{-1}\left(570 \mathrm{~g} \mathrm{week}^{-1}\right)$, which is equivalent to the alcohol in six $12 \mathrm{oz}$ beers.

The median quantity of pulque consumed per drinking event was 0.5 litres ( $24 \mathrm{~g}$ of ethanol). Table 1 shows that half a litre of pulque provides an estimated $215 \mathrm{kcal}$, $23.5 \mathrm{~g}$ of ethanol, plus significant quantities of ascorbic acid, iron, thiamin and riboflavin. Infrequent drinkers, based on the percentage of days on which consumption was reported, tended to consume as much pulque per drinking event as more frequent drinkers $(r=0.20, P=$ $0.1593, N=51$ ). Therefore, even occasional drinkers may have had episodic intakes of potentially important amounts of alcohol.

The heaviest pulque drinkers, based on mean daily intake, consumed the beverage on a greater proportion of days $(r=0.91, P<0.0001, N=51)$, drank more per drinking event $(r=0.51, P=0.0001, N=51)$, and drank more than once during the day $(r=0.68, P<0.0001$, $N=51)$.

\section{Pulque consumption and maternal diets}

Diets during pregnancy were generally adequate in energy $(2360 \pm 610 \mathrm{kcal}$ or $9.88 \pm 2.55 \mathrm{MJ})$. As repeatedly observed in the industrialised countries, individuals who consumed greater quantities of alcohol showed no compensating decrease in energy from all other food (pregnancy: $r=0.04, P=0.7151$; postpartum: $r=0.02$, $P=0.8548)^{1}$. As a result, heavy pulque consumers had greater energy intakes (pregnancy: $r=0.34, P=0.0040$; postpartum: $r=0.38, P=0.0014)$. The 10 heaviest drinkers during pregnancy consumed a median of $2847 \mathrm{kcal} \mathrm{day}^{-1}$ (11.91 MJ day ${ }^{-1}$ ), or $786 \mathrm{kcal} \mathrm{day}^{-1}$ (3.29 $\mathrm{MJ} \mathrm{day}^{-1}$ ) more than the median energy intake for those 19 women who did not consume pulque.

Median intakes of eight micronutrients fell below twothirds of the Mexican Recommended Dietary Intake (RDI) during pregnancy: vitamin $\mathrm{B}_{6}$, thiamin, riboflavin, vitamin $\mathrm{B}_{12}$, iron, ascorbic acid, vitamin $\mathrm{E}$ and vitamin $\mathrm{A}$ (Table 2) ${ }^{36}$. Biochemical assessments on Solís Valley women have demonstrated widespread deficiencies of iron and vitamin $\mathrm{B}_{12}{ }^{37,38}$. Research on local children, which has examined a broader range of micronutrients, has demonstrated deficiencies of iron, riboflavin, vitamin $\mathrm{B}_{12}$, vitamin $\mathrm{A}$, vitamin $\mathrm{E}$ and zinc ${ }^{39}$.

Pulque is a good source of four of the eight 'problem' micronutrients in Table 2. As would be expected, greater pulque consumption $(N=70)$ was associated with higher intakes of these four (ascorbic acid: $r=0.76, P<0.0001$; iron: $r=0.43, P=0.0002$; riboflavin: $r=0.41, P=$ 0.0004 ; thiamin: $r=0.33, P=0.0053$ ). Additionally, the alcohol and ascorbic acid in the beverage would be expected to increase the bioavailability of iron. Indeed, greater pulque intake during pregnancy, based on dietary recalls taken before a third trimester blood sample, was associated with higher plasma ferritin $(r=0.34, P=$ 0.0148, $N=49)$, but not with haemoglobin $(r=0.07$, $P=0.6332, \quad N=49)$ or haematocrit $(r=0.03, \quad P=$ $0.8563, N=49)$.

Because pulque must be purchased or obtained by barter, variability in pulque intake might potentially influence intake of specific foods such as milk. However, no clear relationships were seen between pulque intake and consumption of other foods (not shown).

\section{Control variables for the infant size and Bayley analyses}

Multiple regression analyses (below) examine the relationships of maternal pulque consumption to infant size,

Table 2 Pregnant women's intakes of micronutrients in this population $(N=70)$

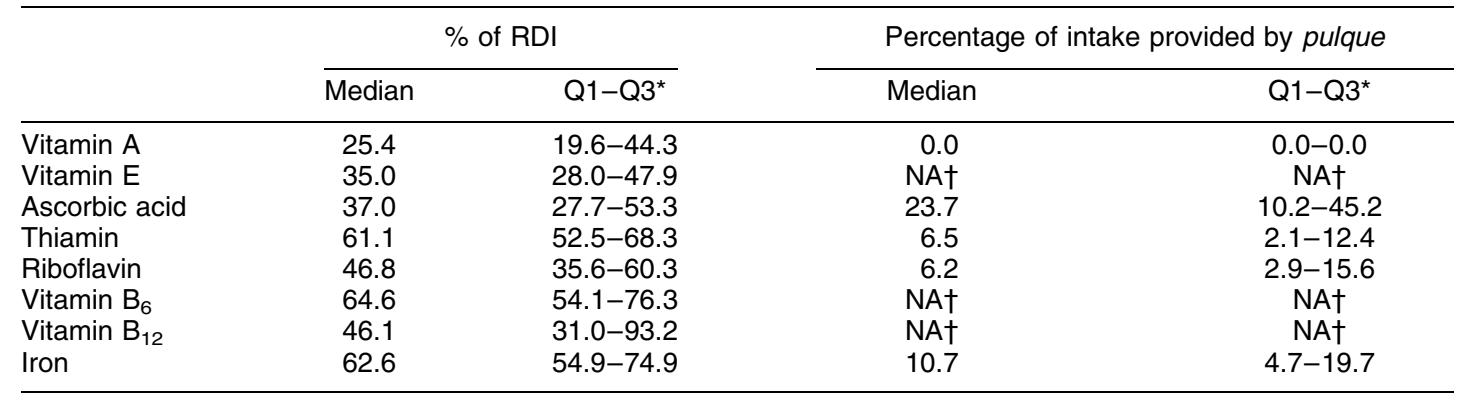

* $\mathrm{Q} 1$ = first quartile (25th percentile), Q3 = third quartile (75th percentile).

$+N A=$ not available. The quantity in pulque, if any, is unknown. 
Table 3 Pearson correlations between potential confounders and the outcome and exposure variables $(N=70)$

\begin{tabular}{|c|c|c|c|c|c|c|c|c|c|c|}
\hline & $\begin{array}{l}\text { Length at } \\
1 \text { month }\end{array}$ & $\begin{array}{l}\text { Linear } \\
\text { growth* }\end{array}$ & Mental & Pulque & $\begin{array}{l}\text { Birth } \\
\text { order }\end{array}$ & $\begin{array}{c}\text { Mother's } \\
\text { height }\end{array}$ & $\begin{array}{l}\text { Mother's } \\
\text { age }\end{array}$ & $\begin{array}{l}\text { Mother's } \\
\text { education }\end{array}$ & $\begin{array}{l}\text { Household } \\
\text { material } \\
\text { wealth }\end{array}$ & $\begin{array}{l}\text { Household } \\
\text { energy } \\
\text { needs }\end{array}$ \\
\hline Length at 1 month & 1.00 & 0.00 & 0.34 & $0.30 \dagger$ & -0.11 & 0.26 & 0.17 & 0.06 & -0.07 & -0.14 \\
\hline Linear growth & & 1.00 & -0.08 & $0.03 \dagger$ & -0.01 & 0.41 & -0.05 & 0.07 & 0.05 & -0.12 \\
\hline Mental (raw) at 6 months & & & 1.00 & 0.13 & -0.09 & -0.03 & 0.12 & 0.07 & 0.07 & -0.01 \\
\hline Pulque & & & & 1.00 & 0.15 & 0.00 & -0.04 & 0.06 & 0.16 & 0.05 \\
\hline Birth order & & & & & 1.00 & -0.08 & -0.80 & -0.22 & -0.08 & 0.59 \\
\hline Mother's height & & & & & & 1.00 & 0.08 & 0.16 & 0.24 & -0.15 \\
\hline Mother's age & & & & & & & 1.00 & 0.33 & 0.04 & -0.39 \\
\hline Mother's education & & & & & & & & 1.00 & 0.20 & -0.07 \\
\hline Household material wealth & & & & & & & & & 1.00 & -0.16 \\
\hline Household energy needs & & & & & & & & & & 1.00 \\
\hline
\end{tabular}

* Measured as residual length at 6 months controlling for length at 1 month.

† Square root of the $R$-square of the multiple regression containing linear and quadratic terms for pulque intake.

growth and Bayley performance. Table 3 shows the Pearson correlations among potential confounders and the outcome and exposure (pulque) variables. Interactions between pulque intake and several variables (including maternal size, infant sex, maternal education and household material wealth) were examined, and none were detected. Because of the small sample size, attempts were made to reduce the number of potential confounders included in the regression analyses (Table 4). In particular, birth order was included as a single variable that contained information on both maternal age and household energy needs. All regression models contain infant sex, maternal education, birth order and household material wealth as control variables. Additionally, the infant size models include the infant's age at measurement and maternal height. For the growth models, the time between measures and maternal height were added as control variables. For the Bayley analyses, age at Bayley administration was added to the regression models.

\section{Pulque intake and infant size at $0-8$ days}

Mexico NCRSP infants tended to be small and to exhibit compromised postpartum growth. At 0-8 days, Solís infants were generally lighter and shorter than the WHO/
NCHS reference (length: $48.8 \pm 1.80 \mathrm{~cm}, N=41$; weight: $3.24 \pm 0.39 \mathrm{~kg}, \quad N=56$; ponderal index: $2.79 \pm 0.42$, $N=41)$. Of 56 infants with weights at $0-8$ days, two children (3.6\%) had low 'birth weights' $(<2.5 \mathrm{~kg})$. Both infants were measured at 8 days postpartum and weighed $2.4 \mathrm{~kg}$. Because the Mexico NCRSP did not assess gestational age, some children may have been born prematurely.

Maternal pulque intake during pregnancy suggested a curvilinear relationship with $0-8$ days weight (not shown). However, a polynomial regression model was not statistically significant. Neither length nor the ponderal index at 0-8 days bore a clear relationship to pulque intake (not shown).

\section{Pulque intake and infant size at 1 month}

At 1 month $(N=70)$, Solís infants tended to be small-forage and slightly heavy-for-length (length-for-age: $-0.99 \pm 0.81 Z$; weight-for-age: $-0.22 \pm 0.68 Z$; weightfor-length: $0.63 \pm 0.67 Z$ ). Stunting was more prevalent (10.0\% of infants) than 'underweight' (weight-for-age: $<-2 Z)(1.4 \%)$. No child had a weight-for-length below $-2 Z$ ('wasted').

Figure 1 plots the relationship between length-for-age

Table 4 Multiple regression models predicting infant size at 1 and 6 months, Bayley mental and motor performance (raw scores), and growth between 1 and 6 months (residual) based on maternal intake of pulque during pregnancy*

\begin{tabular}{|c|c|c|c|c|c|c|c|c|}
\hline & & \multicolumn{2}{|c|}{ Intercept } & \multicolumn{2}{|c|}{ Linear term } & \multicolumn{3}{|c|}{ Quadratic term } \\
\hline & & $B$ & SE & $B$ & SE & $B$ & SE & $P$-value \\
\hline \multirow[t]{2}{*}{1 month $(N=70)$} & Length† & 30.24177 & 7.79104 & 0.03106 & 0.03216 & -0.01066 & 0.00382 & 0.0069 \\
\hline & Weight† & -0.16122 & 1.88707 & 0.00107 & 0.00779 & -0.00180 & 0.00092 & 0.0567 \\
\hline \multirow[t]{4}{*}{6 months $(N=69)$} & Length† & 22.13102 & 10.09092 & 0.03583 & 0.03812 & -0.01053 & 0.00444 & 0.0207 \\
\hline & Weight† & -11.41685 & 4.56349 & -0.01093 & 0.01724 & -0.00178 & 0.00201 & 0.3782 \\
\hline & Mentalł & 36.29157 & 14.11849 & 0.31550 & 0.15264 & -0.03649 & 0.01738 & 0.0399 \\
\hline & Motorł & 12.13188 & 8.32753 & 0.08974 & 0.09003 & -0.01683 & 0.01025 & 0.1058 \\
\hline \multirow[t]{2}{*}{$1-6$ months $(N=69)$} & Length§ & -18.65802 & 5.61452 & -0.01042 & 0.02389 & 0.00170 & 0.02389 & 0.5456 \\
\hline & Weight§ & -8.75525 & 3.20850 & -0.01588 & 0.01365 & 0.00124 & 0.00160 & 0.4414 \\
\hline
\end{tabular}

$\mathrm{B}=$ parameter estimate; $\mathrm{SE}=$ standard error.

* Pulque consumption (kcal) was transformed by use of a square root, and then 'centred' (the mean subtracted) to avoid ill conditioning due to the quadratic term. Mean pulque intake was $78.5 \mathrm{kcal} \mathrm{day}^{-1}$.

† Controlling for gender, age at anthropometry measurement, maternal height, birth order, maternal education and household material wealth

‡ Controlling for gender, age at Bayley measurement, birth order, maternal education and household material wealth.

$\S$ Controlling for gender, time between anthropometry measures, maternal height, birth order, maternal education and household material wealth. 


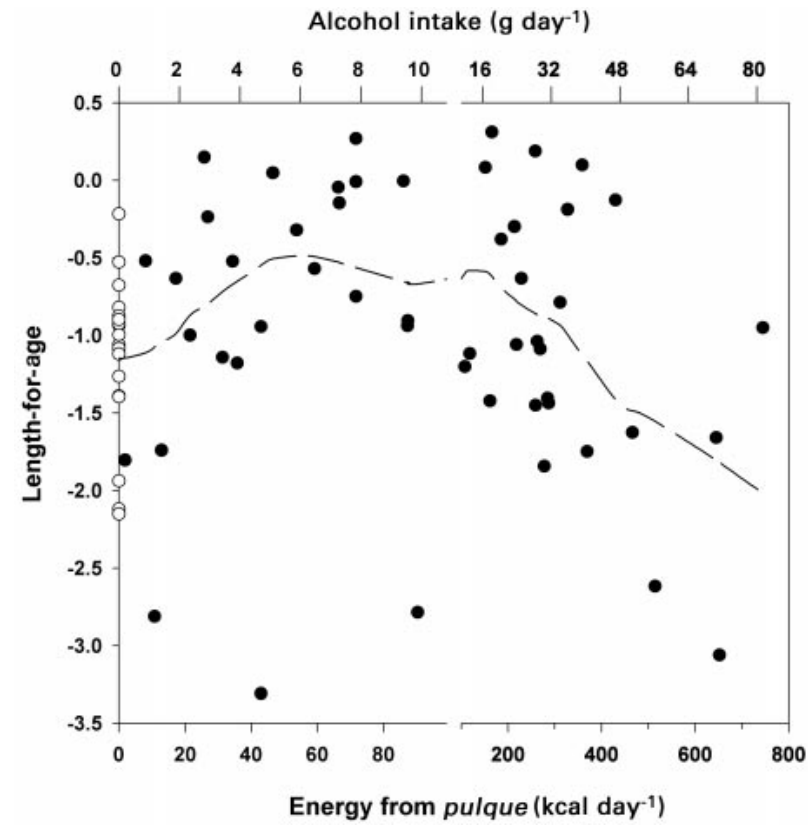

Fig. 1 Scatter plot $(N=70)$ showing the relationship of length-forage $Z$-score at 1 month to average pulque intake during pregnancy. Scale is split to facilitate display of the relationships between length-for-age at 1 month and both very low and high pulque consumptions. 'Non-drinkers' are white circles. Curve was fitted using PROC LOESS

at 1 month and average consumption of pulque during pregnancy. Pulque intake exhibited a clear curvilinear relationship with length-for-age, although the relationship was less obvious for weight-for-age (not shown). In general, the smallest children were clustered at the extremes of pulque intake, while the largest infants had mothers who had consumed small-to-moderate quantities of pulque. The loess curve, a robust estimate of the relationship, suggests a decline in length-for-age with pulque intakes above $54 \mathrm{kcal}$ day $^{-1}$ ( $41 \mathrm{~g}$ ethanol week ${ }^{-1}$ ).

Polynomial regression models, including a quadratic term for maternal pulque intake, were used to investigate these curvilinear relationships. Average pulque intake was transformed (square root) to improve normality and to better approximate the loess curves. Dependent variables were weight and length rather than $Z$-scores. Adjusted for the control variables, the curvilinear (quadratic) term was statistically significant for length (Table 4), but did not reach statistical significance for weight $(P=0.0567)$. Based on the regression equations, the highest predicted weights and lengths at 1 month were associated with pulque intakes of approximately $80-110 \mathrm{kcal} \mathrm{day}^{-1}$ or 61-84 $\mathrm{g}$ alcohol week ${ }^{-1}$. Intakes above or below these were associated with declining size.

\section{Pulque intake and infant size at 6 months and growth from birth to 6 months}

Adjusted for the control variables, the associations between maternal pulque intake and both length and weight at 6 months were weakened in comparison to 1 month, although length retained a statistically significant curvilinear relationship with pulque consumption (Table 4). Multiple regression models showed no relationship of pulque intake during pregnancy to length and weight growth between 1 and 6 months as measured by the 'residual method' (Table 4$)^{25}$.

\section{Pulque and Bayley performance}

The average age at the time of administration of Bayley Scales was $6.1 \pm 0.5$ months. Mean raw scores were $60.9 \pm 6.7$ on the mental scale, and $25.7 \pm 5.1$ on the motor scale. After adjusting for age using the Bayley norms, the average scores were $79.7 \pm 14.6$ on the MDI (mental) and $95.5 \pm 18.3$ on the PDI (motor) scales. Because these values fall below 100 (the Bayley 'norm'), these data indicate delays in development, particularly in mental development, as compared with US children. No significant gender differences were seen in either mental or motor performance.

Figure 2 shows the relationship between pulque intake in pregnancy and Bayley mental performance. As with infant length, low mental scores at 6 months were associated with very high intakes of pulque, while intakes of up to $\sim 120 \mathrm{kcal} \mathrm{day}^{-1}$ (92 $\mathrm{g}$ ethanol week ${ }^{-1}$ ) were associated with better scores. Because of minor variation in age, negative correlations between the 'normed' scores and age, and concerns about the validity of applying US norms to rural Mexican children, polynomial regression

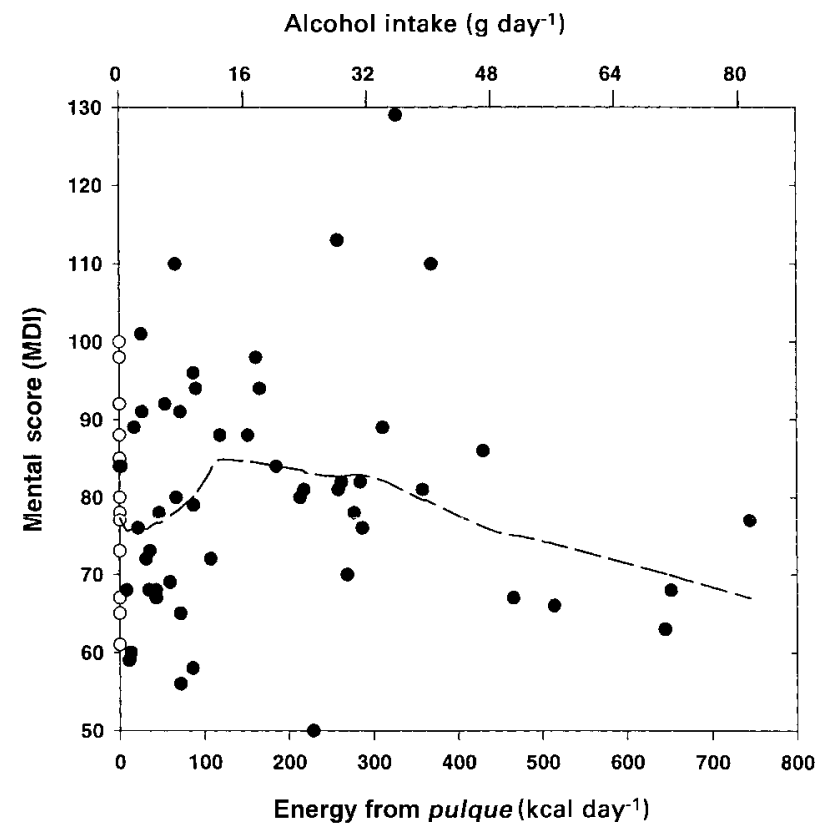

Fig. 2 Scatter plot $(N=70)$ showing the relationship between Bayley mental scores (MDI) at 6 months and average pulque intake during pregnancy. Curves were fitted using PROC LOESS. White circles indicate 'non-consumers' 
analyses employed raw Bayley scores. Adjusting for the control variables, maternal pulque intake during pregnancy was associated with variation in infant mental performance, but not with motor performance (Table 4). One highly influential outlier, an extremely low mental score, was omitted from these analyses. Based on the regression equation, the highest predicted mental scores occurred with pulque intakes of 170-180 kcal day ${ }^{-1}$, or 130-138 g ethanol week ${ }^{-1}$.

An examination of Fig. 2 suggested that the decline in mental performance with higher pulque intake was largely due to four infants of heavy pulque drinkers. When infants of the heaviest drinkers $\left(>450 \mathrm{kcal} \mathrm{day}^{-1}\right.$ from pulque) were eliminated from the mental score analyses, the quadratic (non-linear) term lost statistical significance. Instead, higher pulque consumption during pregnancy (a main effect) was associated with higher mental scores at 6 months $(t=2.35, P=0.0222, N=65)$.

\section{Discussion}

More than 50 years ago, researchers in central Mexico emphasised the importance of pulque in rural diets, noting its consumption by both women and $\operatorname{men}^{40,41}$. In the mid-1980s, pulque remained a prominent component of Solís Valley diets; during the period of study, just six foods (tortillas, onions, sugar, vegetable oil, tomatoes and garlic) were consumed more frequently by valley households $^{21}$. Anecdotal information suggests that the beverage continues to be an important part of contemporary diets in rural, central Mexico.

Laboratory analyses, although dated, show pulque can be a good source of ascorbic acid, riboflavin, iron and thiamin - all nutrients consumed in relatively low amounts by many Mexico NCRSP women. Therefore, even modest consumption of the traditional beverage has the potential to significantly increase intakes of key micronutrients, and to improve nutritional status. The potential significance of pulque as a micronutrient source is indicated by our unpublished research on the iron status of 125 non-pregnant Mexico NCRSP women. For these women, pulque was the leading dietary source of ascorbic acid, and the third leading source of iron (after tortillas and legumes). Moreover, greater pulque consumption during the 12 months prior to blood collection was predictive of higher iron stores, and decreased risk of a low haematocrit and haemoglobin.

Unfortunately, alcohol intakes during pregnancy, the result of pulque consumption, were often quite high among these women. By our calculations, nearly a third of infants were exposed to moderate-to-high average intakes of ethanol during gestation. Moreover, because the amount of pulque consumed per drinking event was only weakly related to the frequency of consumption, even occasional drinkers may have episodically exposed their foetus to potentially harmful amounts of alcohol.
Animal studies suggest that high peak blood alcohol levels are more likely to adversely effect foetal development than regular, low-level exposure ${ }^{42}$.

Despite its likely public health significance, little has been published on the relationship of pulque intake to infant growth and development. In one of the few papers on the topic, Flores-Huerta et al. reported a high prevalence of low birth weight among 32 infants of Mexican mothers who consumed pulque during the prenatal period $^{43}$. More recently, a cross-sectional study of 416 Solís Valley children found low weights-for-age $(<-2 Z)$ were associated with paternal intake of pulque, a variable that may well have been a proxy for prenatal exposure to alcohol ${ }^{44}$.

The current paper, to the best of our knowledge, is the first to use longitudinal data to examine the relationship between maternal pulque intake during pregnancy and subsequent infant growth and development. Our analyses document curvilinear relationships between pulque intake and both child size and Bayley mental performance. Based on the polynomial regression models, intakes in excess of $61-84 \mathrm{~g}$ ethanol week ${ }^{-1}$ were associated with decreasing size at both 1 and 6 months; the inflection point was approximately 50\% higher for Bayley mental scores (at approximately 130-138 g ethanol week ${ }^{-1}$ ). Researchers have identified a broad range of thresholds above which maternal alcohol intakes have been associated with adverse effects in children ${ }^{15}$. And, our threshold values are broadly comparable with those reported in the literature ${ }^{45-47}$. However, our analyses also suggest a beneficial effect of low alcoholic beverage intake, which, if not due to confounding (including a generally better diet), may be attributable to the micronutrient content of pulque.

Although intriguing, a putative beneficial effect of lowto-moderate pulque consumption on child growth and development should be viewed with caution, particularly in view of the established dangers of alcohol and several limitations in study design. First, the sample size was relatively small, which limited our statistical ability to (1) detect subtle effects, (2) fully characterise complex curvilinear relationships, and (3) investigate potential interactions among the alcohol consumption, nutrient intake and household environment variables. Second, maternal pulque consumption was in all likelihood imperfectly measured, and occasional exposure to large amounts of alcohol (at religious festivals, weddings, etc.) very likely occurred and was missed. Lastly, the Mexico NCRSP was a prospective, cohort study, and interpretation should reflect the strengths and weaknesses of such an approach. In particular, a variety of unmeasured, or poorly measured, confounding variables may provide alternative explanations for the observed results. Nevertheless, our results are consistent with an adverse effect of maternal malnutrition during pregnancy on the subsequent size and development of the child. Additional 
research will be needed to identify which nutrients, if any, are involved.

In conclusion, our data show intakes of alcohol by pregnant women were common in these six Solís Valley communities in 1985. Given current scientific knowledge of the adverse effects of ethanol on foetal development, public health interventions are needed to reduce heavy consumption of pulque during pregnancy, while increasing micronutrient intakes, in some areas of rural Mexico.

\section{Acknowledgements}

The authors thank Dr Tiffany Field of the University of Miami for her contributions to the Mexico NCRSP, including the training of staff psychologists in the administration of the Bayley Scales of Infant Development. The Mexico Nutrition CRSP was funded by the US Agency for International Development, grants \# DAN 1309-G-SS-1070 and DAN 1309-A-00-9090-00.

\section{References}

1 Jéquier E. Alcohol intake and body weight: a paradox. Am.J. Clin. Nutr. 1999; 69: 173-4.

2 Mandishona EM, Moyo VM, Gordeuk VR, Khumalo $\mathrm{H}$, Saungweme T, Gangaidzo IT, Gomo ZA, Rouault T, MacPhail AP. A traditional beverage prevents iron deficiency in African women of child bearing age. Eur. J. Clin. Nutr. 1999; 53: $722-5$.

3 de Barrios VB. A Guide to Tequila, Mezcal, and Pulque. Mexico DF: Minutiae Mexicana, 1991

4 Super JC, Vargas LA. The history and culture of food and drink in the Americas. In: Kiple KF, Ornelas KC, eds. The Cambridge World History of Food. Cambridge: Cambridge University Press, 2000; 1248-54.

5 Steinkraus KH, ed. Handbook of Fermented Foods, 2nd edn. New York: Marcel Dekker, 1996.

6 Hernandez M, Chávez A, Bourges H. Valor nutritivo de los alimentos, sa edición. Publicación L12. Mexico DF: Instituto Nacional de la Nutrición, 1980.

7 Murphy SP, Calloway DH, Beaton GH. School children have similarly predicted prevalences of inadequate intake as toddlers in village populations in Egypt, Kenya, and Mexico. Eur. J. Clin. Nutr. 1995; 49: 647-57.

8 Calloway DH, Murphy SP, Beaton GH, Lein D. Estimated vitamin intakes of toddlers - predicted prevalence of inadequacy in village populations in Egypt, Kenya, and Mexico. Am. J. Clin. Nutr. 1993; 58: 376-84.

9 Murphy SP, Beaton GH, Calloway DH. Estimated mineral intakes of toddlers: predicted prevalence of inadequacy in village populations in Egypt, Kenya and Mexico. Am. J. Clin. Nutr. 1992; 56: 565-72.

10 Schultes RE, Raffauf RF. The Healing Forest: Medicinal and Toxic Plants of the Northwest Amazonia. Portland, OR: Dioscorides Press, 1990.

11 Peana AT, Moretti MDL, Manconi V, Desole G, Pippia P. Antiinflamatory activity of aqueous extracts and steroidal sapogenins of Agave americana. Planta Medica 1997; 63: 199-202.

12 Duke JA. CRC Handbook of Medicinal Herbs. Boca Raton, FL: CRC Press, 1985.

13 DeNinno MP, McCarthy PA, Diplantier KC, Eller C, Entienne JB, Zawistoski MP, et al. Steroidal glycocide cholesterol absorption inhibitors. J. Med. Chem. 1997; 40: 2547-54.
14 Schultes RE. Plants of the Gods: Origins of Hallucinogenic Use. New York: McGraw-Hill, 1979.

15 Allebeck P, Olsen J. Alcohol and fetal damage. Alcohol Clin. Exp. Res. 1998; 22: 329S-32S.

16 Bell GL, Lau K. Perinatal and neonatal issues of substance abuse. Pediatr. Clin. North Am. 1995; 42: 268-81.

17 Sokol RJ, Clarren SK. Guidelines for use of terminology describing the impact of prenatal alcohol on the offspring. Alcohol Clin. Exp. Res. 1989; 13: 597-8.

18 ACC/SCN Secretariat. Fourth Report on the World Nutrition Situation. Geneva: ACC/SCN in collaboration with IFPRI, 2000.

19 Martorell R, Habicht J-P. Growth in early childhood in developing countries. In: Falkner F, Tanner RM, eds. Human Growth: A Comprehensive Treatise. New York: Plenum Press, 1986; 241-62.

20 Wachs TD. Relation of mild-to-moderate malnutrition to human development: correlational studies. J. Nutr. 1995; 125: $2245 S-54 S$.

21 Allen LH, Backstrand JR, Chávez A, Pelto GH. Humans Cannot Live by Tortillas Alone: The Results of the Mexico Nutrition CRSP. Final Report to USAID. Storrs, CT: Department of Nutritional Sciences, The University of Connecticut, 1992.

22 Bayley N. Manual for the Bayley Scales of Infant Development. New York: The Psychological Corporation, 1969.

23 World Health Organization (WHO). Measuring Change in Nutritional Status. Geneva: WHO, 1983.

24 Dibley MJ, Goldsby JB, Staehling NW, Trowbridge FL. Development of normalized curves for the international growth reference: historical and technical considerations. Am. J. Clin. Nutr. 1987; 46: 736-48.

25 Willett W. Nutritional Epidemiology, 2nd edn. New York. Oxford University Press, 1998.

26 Murphy SP, Calloway DH. Development of a database for the Nutrition CRSP project. In: Steward RM, ed. Proceedings of the Fifteenth National Nutrient Databank Conference. Ithaca, NY: The CBORD Group, 1991.

27 Cravioto RO, Lockhart EE, Anderson RK, Miranda F, Harris RS. Composition of typical Mexican foods. J. Nutr. 1945; 29 317-29.

28 Cravioto RO, Massieu G, Guzmán J. Composicíon de alimentos mexicanos. Ciencia 1951; 11: 129-55.

29 Sanchez-Marroquin, A., Mexican pulque - a fermented drink from Agave juice. Paper presented at Symposium on Indigenous Fermented Foods, Bangkok, Thailand, 1977.

30 Backstrand JR. Patterns of household food intake in rural, central Mexico. Unpublished Ph.D. dissertation, The University of Connecticut, Storrs, CT, 1990.

31 Backstrand JR, Allen LH, Pelto GH, Chávez A. Examining the gender gap in nutrition: an example from rural Mexico. Soc. Sci. Med. 1997; 44: 1751-9.

32 Joint $\mathrm{FAO} / \mathrm{WHO} / \mathrm{UNU}$ Expert Commission. Energy and Protein Requirements. World Health Organization Technical Report Series 724. Geneva: World Health Organization, 1985.

33 Aiken LS, Stephen SG. Multiple Regression: Testing and Interpreting Interactions. Newbury Park, CA: Sage Publications, 1991.

34 Cohen RA. An introduction to PROC LOESS for local regression. Paper 273 presented at SAS Users Group International 24th Annual Conference, Miami, FL, April 1999.

35 Cleveland WS, Devlin SJ. Locally weighted regression: an approach to regression analysis by local fitting. J. Am. Stat. Assoc. 1988; 83: 596-610.

36 Instituto Nacionál de la Nutrición Salvidor Zubirán (INNSZ). Ingestión diaria recomendada de energia, proteina, vitaminas y minerales para la población mexicana. Mexico DF: INNSZ, 1997.

37 Allen LH, Rosado JL, Casterline JE, Martinez H, López P, Muñoz E, Black AK. Vitamin B-12 deficiency and malabsorp- 
tion are highly prevalent in rural Mexican communities. $\mathrm{Am}$. J. Clin. Nutr. 1995; 62: 1013-9.

38 Black AK, Allen LH, Pelto GH, de Mata MP, Chavez A. Iron, vitamin B-12 and folate status in Mexico: associated factors in men and women and during pregnancy and lactation. $J$. Nutr. 1994; 124: 1179-88.

39 Muñoz EC, Rosado JL, López P, Furr HC, Allen LH. Iron and zinc supplementation improves indicators of vitamin A status of Mexican preschoolers. Am. J. Clin. Nutr. 2000; 71: 789-94.

40 Redfield M. Notes on the cookery of Tepoztlan, Morelos. Am. J. Folk Lore 1929; XIII(164): 167-96.

41 Anderson RK, Calvo J, Serrano G, Payne GC. A study of the nutritional status and food habits of Otomi Indians in the Mezquital Valley of Mexico. Am. J. Pub. Health 1946; 36 : 883-903.

42 West JR, Alkana RL, DeBold JF. Alcohol exposure and altered brain development: present status and implications for future research. In: West JR, ed. Alcohol and Brain Development. New York: Oxford University Press, 1986; 406-27.
43 Flores-Huerta S, Hernandez-Montes H, Argote RM, Villalpando S. Effects of ethanol consumption during pregnancy and lactation on the outcome and postnatal growth of the offspring. Ann. Nutr. Metab. 1992; 36: 121-8.

44 Orozco M, Martínez H, Reyes H, Guiscafré H. A scale without anthropometric measurements can be used to identify low weight-for-age in children less than five years old. $J$. Nutr. 1998; 128: 2363-8.

45 Forrest F, Florey CD, Taylor D. Maternal alcohol consumption and child development. Int. J. Epidemiol. 1992; 21: S17S23.

46 Day NL, Goldschmidt L, Robles N, Richardson G, Cornelius M, Taylor P, Geva D, Stoffer D. Prenatal alcohol exposure and offspring growth at $18 \mathrm{mo}$ : the predictive validity of two measures of drinking. Alcohol Clin. Exp. Res. 1991; 15: 914-8.

47 Goldschimidt L, Richardson GA, Stoffer DS, Day NL. Prenatal alcohol exposure and academic achievement at age six: a nonlinear fit. Alcohol Clin. Exp. Res. 1996; 20: 763-70. 